\title{
Factors influencing surgical success in concomitant horizontal strabismus
}

\author{
Aslihan Uzun', [MD] \\ ORCID: 0000-0002-5787-3879
}

Asena Keles Sahin ${ }^{2}$, [MD]

ORCID: 0000-0002-2700-0866
Preliminary results of this study were presented as Poster Presentation titled "Retrospective analysis of patients who underwent strabismus surgery" at the 51st National Congress of Turkish Ophthalmological Association, October 24-29, 2017, Antalya Turkey.

'Ordu University, Faculty of Medicine, Department of Ophthalmology, Ordu, Turkey.

${ }^{2}$ Ministry of Health, Ordu University, Training and Research Hospital, Ordu, Turkey.

Corresponding Author: Aslihan Uzun Ordu University, Faculty of Medicine, Department of Ophthalmology, Ordu, Turkey.

E-mail: draslihanuzun@gmail.com

https://doi.org/10.32552/2021.ActaMedica.700

\section{n ABSTRACT Con}

Objective: To identify the factors affecting surgical success in patients who underwent horizontal concomitant strabismus surgery.

Materials and Methods: Medical records of 143 patients who underwent concomitant horizontal strabismus surgery and who were followed up at least 6 months at Ordu University, Faculty of Medicine, Department of Ophthalmology between January 2015 and December 2020 were reviewed retrospectively. Surgical success was defined as postoperative orthophoria or deviation angle of 10 prism diopters (PD) or less at 6 months after surgery.

Results: 101 (70.63\%) patients with esotropia and 42 (29.37\%) patients with exotropia were operated. The mean follow-up period was 18.54 \pm 17.51 months, the mean distance and near preoperative deviation were $46.94 \pm 11.62$ PD and $47.29 \pm 11.81$ PD, respectively. The surgical success was $83.92 \%$ in all patients, $87.13 \%$ in esotropic patients, and $76.19 \%$ in exotropic patients. Additional surgery was performed in 8 (5.59\%) patients with $>20$ PD residual strabismus in the following year. Preoperative distance and near deviations were found to be significantly related with surgical success $(p=0.020$ and $p=0.026$ ). As the preoperative deviation decreases, the surgical success increases significantly. The deviation type, age at onset, age at the time of surgery, the interval between diagnosis and surgery, gender, or preoperative amblyopia were not significantly related to surgical success $(p>0.05)$.

Conclusion: The surgical success was found to be high following concomitant horizontal strabismus surgery. Since the preoperative deviation angle is the significant factor determining surgical success, preoperative evaluations should be done carefully. Patients and their parents should also be warned about the probability of additional surgery.

Keywords: Strabismus, esotropia, exotropia

Received: 22 October 2021, Accepted: 25 November 2021,

Published online: 30 November 2021 


\section{INTRODUCTION}

The aim of the treatment in patients with strabismus is to prevent amblyopia, to achieve binocular vision, and to ensure normal visual development by ensuring the parallelism of the visual axes, especially in the younger age group. Strabismus may also lead to aesthetic concerns in untreated adults [1]. The treatment of strabismus also provides the correction of abnormal head position and diplopia, widening and centralization of the visual field, and increasing stereopsis [1]. The prevalence of strabismus has been reported to be $1.68-3.55 \%$ in different studies [2-4]. In a study conducted by reviewing the records of more than 30 million patients in the United States, the frequency of strabismus was found to be $2.75 \%$, the rate of strabismus surgery within 4 years was $0.13 \%$ in those patients, and the need for re-surgery within 1 year was $6.72 \%$ [5].

Strabismus is relatively uncommon in ophthalmology practice, but it has been shown that one out of every 20 strabismus patients requires surgery [5]. In addition, there are studies showing that the quality of life of patients with ocular misalignment is negatively affected due to functional and psychosocial aspects $[1,6]$. It is clear that appropriate optical corrections and, if necessary, surgical treatment are required in patients with squint. Identifying the factors affecting postsurgical success in patients who are scheduled for surgery due to ocular misalignment plays an important role in planning the surgery and increasing postsurgical success. Therefore, this study aimed to evaluate the factors affecting surgical success in patients with horizontal concomitant strabismus.

\section{MATERIALS and METHODS}

Medical records of all patients who were operated for ocular misalignment between January 2015 and December 2020 were reviewed retrospectively. Patients who underwent concomitant horizontal strabismus surgery and were followed up for at least 6 months were included in the study. Patients with paralytic or restrictive strabismus were excluded. Study procedures were conducted in accordance with the principles of the Declaration of Helsinki. Prior to the study, ethical approval was obtained from the Ordu University Clinical Research Ethics Committee (approval no.: 2021/131).

\section{Clinical Evaluation}

All preoperative and postsurgical evaluations were performed by the same ophthalmologist. After obtaining patients' medical history, detailed ophthalmological examinations were performed. Visual acuity was evaluated by the fixation and follow pattern for noncooperative patients, and a Snellen chart was used for cooperative patients. Extraocular muscle functions were examined in the nine cardinal gaze positions. The type of deviation was determined by an alternating cover test. The objective angle of deviation for distance and near were recorded in prism diopters (PD) using alternate prism cover test, with and without spectacles. For noncooperative patients and those with poor fixation, the objective angle of deviation was measured with the Krimsky test. For cooperative patients, binocular vision was evaluated using the Worth's Four Dot test, whereas stereopsis was evaluated using the Titmus test. Following the first examination, $1 \%$ cyclopentolate hydrochloride eye drops were administered to all patients twice in 15-minute intervals, and after 30 minutes, cycloplegic refraction was measured by retinoscopy. Appropriate optical corrections were prescribed according to deviation types and refractive errors. Furthermore, anterior segment and dilated fundus examinations were performed. In patients whose visual acuity could be measured, a difference of two or more lines between the two eyes was considered as amblyopia. Occlusion therapy was initiated for patients (of age $<13$ ) with amblyopia or unilateral eye deviation. Before scheduling surgery, all examinations were repeated at least three times, and surgical treatment was recommended for patients with a horizontal deviation of $>20$ PD despite having an appropriate optical correction.

\section{Surgical Planning}

The surgical method was chosen according to the age of the patient, the presence of amblyopia, the type of deviation and the existence of alternation. While unilateral surgery was performed for the deviated eye in older patients with monocular deviation, bilateral surgery was preferred in 
younger patients with alternating squint. In patients with accompanying inferior oblique overaction or dissociated vertical deviation, inferior oblique recession or anterior transposition was performed in the same session, whereas in patients with $\mathrm{A}$ or $\mathrm{V}$ pattern, a vertical transposition surgery was applied to the horizontal muscles according to pattern and deviation types. The amounts of recession and resection were decided according to the tables in the "American Academy of Ophthalmology, Basic and Clinical Science Course" series [7].

\section{Surgical Treatment}

All patients and parents of children under the age of 18 were informed about the surgery, and a written informed consent was obtained before the surgery. All surgeries were performed under general anesthesia and by the same experienced surgeon. Conjunctival incisions were performed with limbal approach in adults and with fornix incisions in children. Following conjunctival incision, the extraocular muscle was grabbed with a muscle hook. The Tenon's capsule around the muscle was cleaned via blunt dissection, and recession and resection surgeries were performed on the horizontal muscles as planned before. Inferior oblique weakening surgery or pattern surgery according to the pattern and deviation types were performed in the same session. Absorbable $6 / 0$ vicryl sutures with double spatula needles were used for suturing the muscles to the sclera, and absorbable $8 / 0$ vicryl suture was used for conjunctival closure.

\section{Postsurgical Follow-up}

After surgery, all patients were prescribed a combined antibiotic and steroid eye drops, four times daily for two weeks. The patients were examined on the 1 st postoperative day; 2 nd, 4 th, and 6 th months; and later when deemed necessary. In the 6th month, orthophoria or a deviation of 10 PD or less was considered as surgical success, whereas if patients had a deviation greater than 10 $P D$, it was considered as surgical failure.

\section{Statistical Analysis}

SPSS Statistics version 21.0 (SPSS Inc., Chicago, IL, USA) package program was used for statistical analyses. The conformity of the variables to normal distribution was evaluated using KolmogorovSmirnov test. Mean and standard deviation were used to present descriptive analyses. Categorical variables were expressed as frequency and percentage and compared using Pearson's chisquare test. Mann-Whitney U Test was used for evaluating nonparametric variables that did not show normal distribution between the two groups. A P-value of 0.05 or less was considered statistically significant.

\section{RESULTS}

A total number of 143 patients who underwent concomitant horizontal strabismus surgery and were followed up for at least 6 months in our clinic were included in the study. Demographic characteristics of all patients are given in Table 1. The time from the onset of deviation to surgery ranged from 2 months to 47 years, with a mean of 94.97 months. Before surgery, the mean deviation angle with spectacles were $46.94 \pm 11.62(20-90)$ PD and 47.29 \pm 11.81 (20-90) PD for distance and near, respectively.

Data are given as mean \pm standard deviation for continuous variables according to the normality of the distribution, and frequency (percent) for categorical variables.

Of the patients included in the study, 101 (70.63\%) underwent surgery due to esotropia and 42 (29.37\%) due to exotropia. The age of onset of deviation was $34.58 \pm 29.51$ months in patients with esotropia, and it was $87.17 \pm 58.53$ months in patients with exotropia $(p<0.001)$. The deviation angle was 45.72 \pm 10.52 PD in patients with esotropia, whereas it was $51.9 \pm 15.89$ PD in patients with exotropia.

Nine patients (6.29\%) had a previous history of strabismus surgery. Six (4.2\%) of these patients with residual deviation had undergone bilateral

Table 1. Demographic characteristics of patients

\begin{tabular}{|l|c|}
\hline Variables & $\mathrm{n}=143$ \\
\hline Gender & \\
$\quad$ Female & $78(54.55 \%)$ \\
Male & $65(45.45 \%)$ \\
Age at onset of deviation (months) & $50.03 \pm 46.70$ \\
Age at surgery (months) & $145.62 \pm 143.47$ \\
Time between diagnosis and surgery & $94.97 \pm 116.50$ \\
(months) & \\
The mean follow-up period (months) & $18.54 \pm 17.51$ \\
\hline
\end{tabular}


medial rectus recession, and 3 (2.1\%) patients had undergone bilateral lateral rectus recession.

The preoperative clinical characteristics of patients are given in Table 2. Bilateral strabismus surgery was performed in 126 (88.11\%) patients [86 $(60.14 \%)$ and 31 (21.68\%) of them underwent bilateral medial and lateral rectus recessions, respectively; the remaining $3(2.1 \%)$ and $6(4.2 \%)$ patients underwent bilateral medial and lateral rectus resections, respectively], and unilateral recession and resection surgeries were performed in $17(11.89 \%)$ patients. In 19 (13.29\%) patients with $2+$ or more inferior oblique overaction, in addition to horizontal muscle surgery, inferior oblique weakening surgery was performed in the same session. Additionally, in 14 (9.79\%) patients, vertical transposition of horizontal muscles was performed according to the pattern and deviation types. The mean amount of recession performed for medial and lateral rectus muscles was $6.42 \pm 1.39 \mathrm{~mm}$, and the mean amount of resection was $7 \pm 1.26 \mathrm{~mm}$. None of the patients developed any complications during or after surgery.

Surgical success was achieved in 120 (83.92\%) patients as per the 6th month postsurgical followup, whereas a residual deviation more than 10 PD was detected in 23 (16.08\%) patients. The surgical success rate was $87.13 \%$ in patients with esotropia, and it was $76.19 \%$ in patients with exotropia. The postsurgical success according to the deviation

Table 2. Preoperative clinical characteristics of patients $(n=143)$

\begin{tabular}{|c|c|}
\hline Variables & Number of patients (\%) \\
\hline \multicolumn{2}{|l|}{ Diagnosis } \\
\hline Esotropia & $101(70.63 \%)$ \\
\hline Infantile ET & $24(16.78 \%)$ \\
\hline Partially accommodative ET & 30 (20.98\%) \\
\hline Non-refractive ET & 47 (32.87\%) \\
\hline Exotropia & $42(29.37 \%)$ \\
\hline Infantile XT & $3(2.10 \%)$ \\
\hline Constant XT & $30(20.98 \%)$ \\
\hline Sensory XT & $6(4.20 \%)$ \\
\hline Intermittent XT & $3(2.10 \%)$ \\
\hline Amblyopia & $63(44.06 \%)$ \\
\hline DVD & $4(2.80 \%)$ \\
\hline A-pattern & $1(0.70 \%)$ \\
\hline V-pattern & 15 (10.49\%) \\
\hline Inferior oblique muscle overaction & $32(22.38 \%)$ \\
\hline
\end{tabular}

ET: Esotropia, XT: Exotropia, DVD: Dissociated Vertical Deviation.
Table 3. Postsurgical success according to the deviation type

\begin{tabular}{|l|c|c|}
\hline Postoperative deviation & $\begin{array}{c}\text { Esotropia } \\
n=101(\%)\end{array}$ & $\begin{array}{c}\text { Exotropia } \\
n=42(\%)\end{array}$ \\
\hline Orthophoria & $75(74.26 \%)$ & $25(59.52 \%)$ \\
$\leq 10$ PD & $13(12.87 \%)$ & $7(16.67 \%)$ \\
$>10$ PD & $13(12.87 \%)$ & $10(23.81 \%)$ \\
\hline
\end{tabular}

PD: Prism Diopters

type is presented in Table 3. In the following year, additional surgery was performed in 8 (5.59\%) patients with residual deviation more than 20 PD. In this study, consecutive deviation was not observed in any of the patients.

In order to evaluate the factors affecting surgical success, patients were divided into two groups - one with patients who underwent successful surgery and another with surgical failure (Table 4). There was no significant difference between the groups in terms of deviation type, age at onset of deviation, age at surgery, time between diagnosis and surgery, sex, and presence of preoperative amblyopia ( $p>0.05)$. However, it was observed that the surgical success increased significantly when the distance and near deviation angles were less ( $p$ $=0.020$ and $p=0.026$, respectively).

\section{DISCUSSION}

There are many studies in the literature evaluating the success of strabismus surgeries. In different studies, success rates of $60-86.5 \%$ were reported for horizontal concomitant strabismus surgery [8-12]. In our study, the surgical success rate was found to be $83.92 \%$ in patients who underwent surgery for horizontal concomitant deviation. Kampanartsanyakorn et al. reported a success rate of $60.2 \%$ for horizontal strabismus surgery and stated that this was an acceptable rate [8]. They also reported that they did not consider the "surgeon factor" in their study [8]. However, no difference was found when the success rates of strabismus surgeries performed by assistants and specialists were compared in previous studies $[8,13]$. In our study, this bias was prevented by the fact that all preoperative and postsurgical evaluations, surgical planning, and strabismus surgeries were performed by the same ophthalmologist.

In terms of deviation types, our study found that surgical success was higher in patients with 
Table 4. The analysis of surgical success and influencing factors

\begin{tabular}{|c|c|c|c|}
\hline Variables & $\begin{array}{l}\text { Surgical success } \\
\qquad n=120\end{array}$ & $\begin{array}{l}\text { Surgical failure } \\
\qquad n=23\end{array}$ & $P$-value \\
\hline Gender & & & $0.114^{\mathrm{a}}$ \\
\hline Female & $62(79.49 \%)$ & $16(20.51 \%)$ & \\
\hline Male & $58(89.23 \%)$ & $7(10.77 \%)$ & \\
\hline Diagnosis & & & $0.105^{\mathrm{a}}$ \\
\hline Esotropia & $88(87.13 \%)$ & $13(12.87 \%)$ & \\
\hline Exotropia & $32(76.19 \%)$ & $10(23.81 \%)$ & \\
\hline Amblyopia & & & $0.951^{\mathrm{a}}$ \\
\hline$(+)$ & $53(84.13 \%)$ & $10(15.87 \%)$ & \\
\hline$(-)$ & $67(83.75 \%)$ & $13(16.25 \%)$ & \\
\hline Age at onset of deviation (months) & $47.48 \pm 44.22$ & $63.30 \pm 57.26$ & $0.200^{\mathrm{b}}$ \\
\hline Age at surgery (months) & $138.39 \pm 138.37$ & $183.35 \pm 165.89$ & $0.105^{b}$ \\
\hline Time between diagnosis and surgery (months) & $90.17 \pm 113.62$ & $120.04 \pm 130.38$ & $0.191^{\mathrm{b}}$ \\
\hline Preoperative distance deviation (PD) & $45.53 \pm 9.06$ & $58.00 \pm 21.09$ & $0.020^{\mathrm{b}}$ \\
\hline Preoperative near deviation (PD) & $45.95 \pm 9.41$ & $58.00 \pm 21.09$ & $0.026^{b}$ \\
\hline
\end{tabular}

Data are given as mean \pm standard deviation for continuous variables and frequency (percent) for categorical variables. PD: Prism Diopters, ${ }^{\text {PPearson }}$ chi-square test, bMann-Whitney $U$ test

esotropia (87.13\%) compared to patients with exotropia (76.19\%). Erdol et al. also found a higher success rate in patients with esotropia (92.3\%) compared to patients with exotropia (73.3\%) [11]. Abbasoglu et al. reported an $86 \%$ cosmetic success rate in patients with esotropia and $94 \%$ in patients with exotropia after concomitant horizontal strabismus surgery [14]. The better surgical outcome in esotropia patients in our study can be explained by two reasons. The first is that the amount of presurgical deviation was lower in these patients, and the other is that the age of onset of deviation and, therefore, the age at the time of surgery was lower in esotropia patients, although its effect on surgical success has not been statistically demonstrated. Consistent with our point, Chen et al. reported that esotropia patients benefited more from early surgery compared to exotropia patients in their study in which they compared the surgical results of patients with esotropia and those with exotropia [15].

It has been reported in previous studies that the amount of preoperative deviation affects the surgical outcome in patients with horizontal strabismus $[8-12,16]$. In our study, as the angle of preoperative distance and near deviations increased, surgical success decreased. However, it has been shown that the type of deviation, age of onset of the deviation, age at the time of surgery, time between diagnosis and surgery, sex, and the presence of preoperative amblyopia do not affect surgical success. Gezer et al. reported that surgical success was lower in patients who underwent surgery for exotropia with a higher preoperative deviation angle and a higher myopic refractive error [17]. Erdol et al. stated that the greater is the amount of preoperative deviation, the higher is the residual deviation angle and suggested that the amount of surgery should be slightly more than that recommended in previous charts in order to increase the surgical success in patients with large angle deviations [11]. Abbasoglu et al. stated that many pre, intra, and postsurgical factors, especially the experience of the physician during the preoperative evaluation, the prismatic effect of the glasses used by the patient, and incorrect conversions (from PD to degree) of the measured deviation angle, may affect the surgical outcome [14].

In studies evaluating postsurgical success in patients with concomitant horizontal strabismus, the effect of anisometropia was also investigated, but it was shown that it did not affect the surgical outcome $[12,14]$. In our study, anisometropia was not included in the statistical evaluation since the number of patients with a difference of $\geq 2.00 \mathrm{D}$ (in spherical equivalent) between the two eyes was very low. Additionally, since visual acuity, fusion, and stereopsis could only be measured in cooperative patients in our study, their effects on postsurgical success could not be evaluated. 
Another factor that has an effect on success after strabismus surgery has been investigated is axial length. Kushner et al. showed that axial length had no effect on postsurgical success in patients with strabismus [16]. Beisse et al. suggested that considering the prismatic effect of glasses and the axial length when planning the surgery would increase the surgical success, especially in patients with esotropia and hyperopia above 2.00 D [18]. Since the axial length is not routinely measured in patients who undergo surgery for strabismus, the effect of axial length on surgical success could not be evaluated in our study. Another limitation of our study is also that the deviation angles of patients using optical correction were measured with spectacles, and the prismatic effect of glasses was not taken into account in these patients.

\section{CONCLUSION}

Our study showed that the most important factor affecting surgical success in horizontal concomitant strabismus is the amount of preoperative deviation. The surgical success is lower and residual deviation is higher in patients with a large preoperative deviation angle. The need for greater recession or resection of the extraocular muscles and the increase in the number of extraocular muscles that require intervention in patients with a large preoperative deviation angle, may decrease the surgical success. Measuring the angle of deviation with maximum care and carefully planning the strabismus surgery can increase postsurgical success rates. In addition, during the preoperative evaluation, patients and their parents should be informed about the possibility of residual deviation and the need for another surgery.

\section{CONFLICT Of INTEREST}

The authors decline any actual or potential conflict of interest.

\section{we REFERENCES Cem}

[1] Ribeiro Gde B, Bach AG, Faria CM, et al. Quality of life of patients with strabismus. Arq Bras Oftalmol. 2014; 77(2): 110-3. doi: 10.5935/0004-2749.20140027. PMID: 25076476 .

[2] Griffith JF, Wilson R, Cimino HC, et al. The Use of a Mobile Van for School Vision Screening: Results of 63841 Evaluations. Am J Ophthalmol. 2016; 163: 108-114.e1. doi: 10.1016/j.ajo.2015.11.026. Epub 2015 Nov 24. PMID: 26621684.

[3] Hashemi H, Yekta A, Jafarzadehpur E, et al. The prevalence of strabismus in 7-year-old school children in Iran. Strabismus. 2015; 23(1): 1-7. doi: 10.3109/09273972.2014.999795. Epub 2015 Jan 13. PMID: 25584828.

[4] Friedman DS, Repka MX, Katz J, et al. Prevalence of amblyopia and strabismus in white and African American children aged 6 through 71 months the Baltimore Pediatric Eye Disease Study. Ophthalmology. 2009; 116(11): 212834.e1-2. doi: 10.1016/j.ophtha.2009.04.034. Epub 2009 Sep 16. PMID: 19762084; PMCID: PMC2783780.

[5] Repka MX, Lum F, Burugapalli B. Strabismus, Strabismus Surgery, and Reoperation Rate in the United States: Analysis from the IRIS Registry. Ophthalmology. 2018; 125(10): 1646-1653. doi: 10.1016/j.ophtha.2018.04.024. Epub 2018 May 18. PMID: 29779683.
[6] Hatt SR, Leske DA, Castañeda YS, et al. Association of Strabismus with Functional Vision and Eye-Related Quality of Life in Children. JAMA Ophthalmol. 2020; 138(5): 528535. doi: 10.1001/jamaophthalmol.2020.0539. PMID: 32215586; PMCID: PMC7099455.

[7] Raab EL, Aaby AA, Bloom JN, et al. Pediatric Ophthalmology and Strabismus. Skuta GL, Cantor LB, Weiss JS (Eds). American Academy of Ophthalmology Basic and Clinical Course Section: 06, San Francisco, CA 2010; 145-162.

[8] Kampanartsanyakorn S, Surachatkumtonekul T, Dulayajinda D, et al. The outcomes of horizontal strabismus surgery and influencing factors of the surgical success. J Med Assoc Thai. 2005; 88 Suppl 9: S94-9. PMID: 16681059.

[9] Yasar T, Simsek S, Ozdemir M. Horizontal konkomitan sasiliklarda cerrahi sonuclarin sasilik tipi, derecesi ve cerrahi teknigi ile iliskisi. MN Oftalmoloji. 2002; 9: 70-3.

[10] Sen ErkekE, Unlu MK, Vergili N, et al. Konkomitan horizontal sasiliklarda cerrahi tedavi sonuclarimiz. MN Oftalmoloji. 1996; 5: 293-7.

[11] Erdol H, Imamoglu I, Elmas R. Sasilik cerrahisinde basariyi etkileyen faktorler. T Oft Gaz. 2000; 30: 192-7.

[12] Yilmaz Cinar FG. Cocukluk cagi edinsel komitan ezotropyalarda cerrahi sonuclar. Cukurova Med J. 2020; 45(4): 1449-1458. 
[13] Crouch ER Jr. A comparison of the success rates of resident and attending strabismus surgery: discussion. J Pediatr Ophthalmol Strabismus. 1993; 30(3): 157-8. PMID: 8350224.

[14] Abbasoglu OE, Sener EC, Sanac AS. Factors influencing the successful outcome and response in strabismus surgery. Eye (Lond). 1996;10 (Pt 3): 315-20. doi: 10.1038/ eye.1996.66. PMID: 8796155.

[15] Chen YW, Lin SA, Lin PW, et al. The difference of surgical outcomes between manifest exotropia and esotropia. Int Ophthalmol. 2019;39(7): 1427-1436. doi: 10.1007/s10792018-0956-5. Epub 2018 Jun 19. PMID: 29922977.
[16] Kushner BJ, Fisher MR, Lucchese NJ, et al. Factors influencing response to strabismus surgery. Arch Ophthalmol. 1993; 111(1): 75-9. doi: 10.1001/ archopht.1993.01090010079030. PMID: 8424728.

[17] Gezer A, Sezen F, Nasri N, et al. Factors influencing the outcome of strabismus surgery in patients with exotropia. J AAPOS. 2004; 8(1): 56-60. doi: 10.1016/j. jaapos.2003.08.006. PMID: 14970801.

[18] Beisse F, Koch M, Uhlmann L, et al. Consideration of eyeball length and prismatic side-effects of spectacle lenses in strabismus surgery-a randomised, double-blind interventional study. Graefes Arch Clin Exp Ophthalmol. 2020;258(6):1319-1326. doi: 10.1007/s00417-020-04690-z. Epub 2020 Apr 29. PMID: 32350650. 